ÖGUM-Mitteilungen

Österreichische Gesellschaft für Ultraschall

\title{
ÖGUM-WEBINARE 2021
}

\section{ÖGUM Webinare}

24.03.2021

Christian Aiginger (Wien)

„Appendizitis und Differenzialdiagnosen im klinischer Alltag - vom Symptom zur Therapie

- Problem interdisziplinär gelöst"

\subsubsection{1}

Elisabeth Skalla-Oberherber (Innsbruck)

"Sonografisch geführte Schmerztherapie“

05.05.2021

Martina Kollmann, Monika Wölfler (Graz) „Ultraschall in der Fertilitätsdiagnostik“

\subsubsection{1}

Friedrich Aigner, Leo Pallwein-Prettner (Innsbruck)

„Multiparametrischer Ultraschall des Skrotums“

\subsubsection{1}

Horst Steiner (Salzburg)

„Themen aus der Frühschwangerschaft und Pränataldiagnostik“

\subsubsection{1}

Renata Pospischill (Wien)

„Sonografie der Säuglingshüfte 2021: Bewährtes, Neues, Sinnhaftigkeit des sonografischen Hüftscreenings - wohin wird es gehen?“

\section{Kosten: kostenfrei}

DFP: Pro Webinar kann 1 DFP-Punkt erworben werden.

Die Anmeldung erfolgt über die ÖGUMWebsite (www.oegum.at).

\section{Ultraschall 2021}

\section{7.-29. Oktober 2021 Messe Wien}

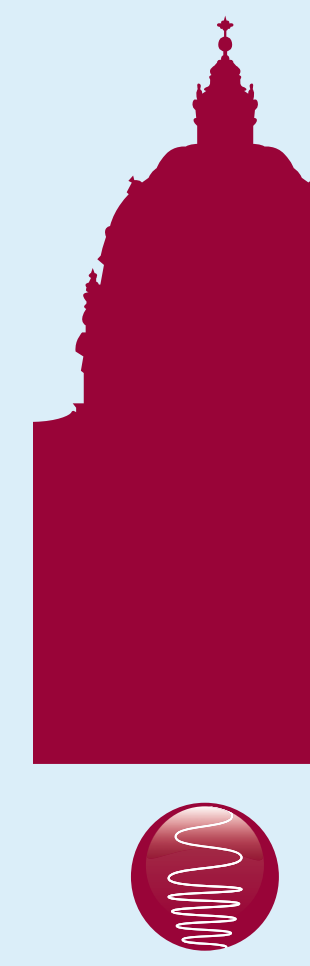
www.ultraschall2021.at

44. Dreiländertreffen der ÖGUM / DEGUM / SGUM 